\title{
Polyclonal Immunoglobulin Secretion in Patients with Common Variable Immunodeficiency Using Monoclonal B Cell Differentiation Factors
}

\author{
L. Mayer, S. M. Fu, C. Cunningham-Rundles, \\ and H. G. Kunkel \\ Department of Immunology, The Rockefeller University, and \\ Memorial Sloan-Kettering Cancer Center, New York, \\ New York 10021
}

bstract. B cells from 25 patients with common variable immunodeficiency (CVI) were tested for their ability to differentiate under the influence of $B$ cell differentiation factors (BCDF), derived from $\mathrm{T}$ cell hybridomas or $\mathrm{T}$ cell clones. 11 patients generated Ig plaque-forming cells in the range comparable to that of normal controls with supernatant from the $T$ cell hybrid MOP $1 \mathrm{~L}$. With various hybrid or clone supernatants, differing response patterns emerged. Four patients who failed to respond to MOP $1 \mathrm{~L}$ responded to $T$ cell clone supernatant RAC. Another who failed to respond to both MOP $1 \mathrm{~L}$ and RAC responded to $\mathrm{T}$ cell hybrid supernatant MTP 7. These results indicate that these supernatants contain different BCDFs and suggest heterogeneity in the differentiation states of B cells in CVI. In addition, three patients demonstrated exaggerated responses to BCDF, and evidence was obtained from B cells of these patients for increased BCDF receptor density. Thus, the accumulated evidence indicates that $\mathrm{T}$ cell defects may be a primary pathogenetic mechanism in common variable immunodeficiency, and purified BCDF may be of therapeutic value.

\section{Introduction}

Common variable immunodeficiency (CVI) ${ }^{1}$ is a heterogenous disorder characterized by pan-hypogammaglobulinemia with normal or decreased circulating $\mathrm{sIg}^{+}$cells. Although intrinsic B cell defects have been postulated to be primary pathogenetic

Address reprint requests to Dr. L. Mayer, Mount Sinai Hospital, Annenberg 23-08, 1 Gustave Levy Place, New York 10029. Dr. Fu's current address is Oklahoma Medical Research Foundation, Oklahoma City, OK 73104.

Received for publication 10 May 1984.

J. Clin. Invest.

(c) The American Society for Clinical Investigation, Inc. 0021-9738/84/12/2115/06 $\$ 1.00$

Volume 74, December 1984, 2115-2120 factors in most patients (1-6), evidence is being accumulated to suggest the presence of various $T$ cell abnormalities. Waldmann et al. (7) as well as others (8-11) described patients with CVI and active T cell suppression. More recently, absent T cell helper activity was reported in one patient with the absence of a T4 helper/inducer $\mathrm{T}$ cell subset (12). There are also reported defects in monocytes $(8,13)$. These findings indicate the complexity of this disorder.

Despite the multiple cellular defects, the arrest in B cell differentiation in CVI patients offers a good opportunity for the study of factors influencing such differentiation. To this end, we recently generated a series of human $T$ cell hybridomas secreting factors that induce $\mathrm{B}$ cell maturation to antibody secreting cells (B cell differentiation factors, BCDF). Using these factors in vitro, we have been able to induce $B$ cell differentiation in the normal range in $>50 \%$ of non- $T$ cells from patients with CVI, including three patients whose response to $\mathrm{BCDF}$ was consistently well above that seen in normal controls. These findings suggest that, given the proper stimulus, B cells from patients with CVI can differentiate and that T cell defects may be the primary pathogenetic factor in these cases. Additionally, a subset of these patients with supranormal responses to $\mathrm{BCDF}$ may represent a $\mathrm{BCDF}$ deficiency state.

\section{Methods}

Patient material. 25 patients meeting the World Health Organization criteria for common variable immunodeficiency (14) were screened from clinics at The Rockefeller University or at Memorial SloanKettering Institute. All patients were pan-hypogammaglobulinemic, with onset after age two. Normal age-matched control volunteers were obtained from the laboratory or The Rockefeller University Hospital clinic.

Cell separation and culture conditions. Peripheral blood (PB) mononuclear cells (MNC) from patients as well as normal control

1. Abbreviations used in this paper: $\mathrm{BCDF}, \mathrm{B}$ cell differentiation factor; CM, culture medium; CVI, common variable immunodeficiency; EBV, Epstein-Barr virus; IL-2, Interleukin 2; MNC, mononuclear cells; PB, peripheral blood; PFC, plaque-forming cells; PWM, pokeweed mitogen; RBC, erythrocyte. 
volunteers were obtained by layering heparinized blood diluted $1: 3$ in phosphate buffered saline (pH 7.2) on a Ficoll-Hypaque gradient (Pharmacia Fine Chemicals, Piscataway, NJ). T/B separation using neuraminidase-treated sheep erythrocytes (RBC) was performed as previously described (15). All cells were cultured in RPMI 1640 (Flow Laboratories, Inc., McLean, VA), 10\% fetal calf serum (Reheis Co., Inc., Phoenix, AZ), $1 \%$ penicillin/streptomycin (Gibco Laboratories, Grand Island, NY), and $2 \mathrm{mM}$ glutamine (Gibco Laboratories)-culture medium (CM). In some cases, pokeweed mitogen (PWM; Gibco Laboratories) was used at a 1:100 dilution. Epstein-Barr virus (EBV) was obtained from the marmoset line B958. A 1-ml aliquot was added to $1 \times 10^{6}$ non-T cells in $\mathrm{CM}$ at the onset of culture. $24 \mathrm{~h}$ later, $1 \mathrm{ml}$ was removed and replenished with fresh CM. EBV-infected cultures were fed every $3 \mathrm{~d}$ in this manner.

Generation of human T-T hybridomas and BCDF. Lectin stimulated PB or tonsil T cells were fused with mutagenized hypoxanthine guanine phosphoribosyltransferase-deficient $\mathrm{T}$ cell lines and selected in hypoxanthine aminopterin thymidine medium (15). Alternatively, activated $T$ cells were fused with nonmutagenized $T$ cell lines lacking a selectable surface marker (i.e., MOLT4, OKT4) and separated by an indirect rosetting technique using OKT4 (Ortho Diagnostic Systems, Inc., Westwood, MA) and goat anti-mouse IgG-coated ox RBC (Mayer, L., S. M. Fu, and H. G. Kunkel, manuscript submitted for publication). In either case, human $\mathrm{T}$ cell hybrids were isolated and shown to be true hybridomas by HLA or surface marker staining (15). T cell hybridomas were cultured in $\mathrm{CM}$ at $2 \times 10^{5} \mathrm{ml}$ for $48 \mathrm{~h}$. The resultant supernatant was tested for various activities on normal human B cells. Those hybrids (MOP 1L, MTP 7, MOW 9) demonstrating BCDF activity were used in this study. Supernatants from these hybrids were added at $10 \%$ vol/vol to cultured non-T cells.

Additional BCDF was obtained from an Interleukin 2 (IL-2) dependent cloned $T$ cell line (RAC) initially stimulated with phytohemaglutinin (1:100 dilution; Gibco Laboratories) and maintained at 2 $\times 10^{5}$ cells/ml in CM with $10 \%$ IL-2 (Electro-Nucleonics Inc., Fairfield, NJ). Supernatants were collected $48 \mathrm{~h}$ after addition of IL-2 and used at $0.1 \% \mathrm{vol} / \mathrm{vol}$ with cultured non-T cells.

$B$ cell differentiation assay. Reverse hemolytic plaque assay was performed on day 6 of culture using Staph protein A-coated sheep RBC and a polyclonal developing antisera (rabbit anti-human IgG, IgA, and IgM; Cappel Laboratories, Cochranville, PA) (16). Cultures infected with EBV were assayed on day 10.

$T$ cell suppression assay. One million normal control PB MNC were co-cultured with $1 \times 10^{6} \mathrm{~T}$ cells from patients with CVI or other allogeneic normal controls, and PWM. T cells subjected to a cesium irradiation source $(1,500 \mathrm{rad})$ were added to separate cultures to test for radiosensitivity of suppressor cells. A reverse plaque assay was performed on day 6. Percent suppression was calculated as follows: $100 \times[(\mathrm{PFC} /$ culture $\mathrm{MNC}+\mathrm{CVI} \mathrm{T}) /(\mathrm{PFC} /$ culture $\mathrm{MNC}+$ normal $\mathrm{T})]=$ percent suppression.

Surface and intracytoplasmic immunofluorescence. OKT3, T4, T8, and M1 were obtained from Ortho Diagnostic Systems, Inc.). Fluorescein-conjugated $\mathrm{F}(\mathrm{ab})_{2}^{\prime}$ goat anti-mouse Ig (1:100 dilution) was obtained from Cappel Laboratories. Affinity-purified fluorescein-conjugated $F(a b)_{2}^{\prime}$ rabbit or sheep anti-human IgG, IgA, or IgM were prepared in this laboratory and used as previously described (17). Two hundred thousand MNC, T, or non-T cells were pelleted in 96 well plastic microtiter plates (Dynatech Laboratories, Inc., Alexandria, VA) at $1,000 \mathrm{rpm} \times 4 \mathrm{~min}$, resuspended in 5-10 lambda of primary antibody, and shaken for $30 \mathrm{~min}$ at $4^{\circ} \mathrm{C}$ on a Dynatech Microshaker II (Dynatech Laboratories, Inc.). Wells were washed three times in phosphate buffered saline-1\% bovine serum albumin (PBS-BSA) with 0.02\% sodium azide, and in the case of the monoclonal antibodies, 10 lambda fluorescein-conjugated goat anti-mouse IgG was added for an additional 30 min. Cells were resuspended in RPMI [Hepes $(25 \mathrm{mM})$ and $\mathrm{Na}-$ EDTA $(3 \mathrm{mM})]$ and counted on a cytofluorograph $(30-\mathrm{H}$, Ortho Diagnostic Systems, Inc.) gating for live cells (18). Intracytoplasmic immunofluorescence staining using the above reagents was performed as previously described (15).

\section{Results}

25 patients with CVI (14) were screened for the ability of their non- $T$ cells to differentiate in the presence of two BCDF sources (MOP $1 \mathrm{~L}$ and RAC). As seen in Table I, non-T cells from 11 of the 25 patients were capable of differentiation to Ig-secreting cells in the presence of supernatant from the $T$ cell hybridoma MOP 1L (range, 170-31, 680 plaque-forming cells (PFC)/well). These were the responder patients. However, virtually no differentiation occurred in CM alone (range,

Table I. Effects of BCDF on Non-T Cells in Patients with Common Variable Immunodeficiency

\begin{tabular}{|c|c|c|c|c|}
\hline \multirow[b]{2}{*}{ Patient } & \multicolumn{4}{|l|}{ PFC/well* } \\
\hline & $\begin{array}{l}\text { Medium } \\
\text { control }\end{array}$ & MOP 1L & RAC & EBV \\
\hline C.N. & 65 & 31,420 & 5,260 & 4,280 \\
\hline R.O. & 110 & 31,680 & 4,800 & 2,190 \\
\hline J.A. & 0 & 11,760 & - & 1,070 \\
\hline V.E. & 10 & 4,760 & - & 450 \\
\hline F.E. & 0 & 1,090 & 295 & 110 \\
\hline G.R. & 0 & 1,010 & - & 280 \\
\hline S.T. & 0 & 940 & 1,600 & 180 \\
\hline S.I. & 0 & 600 & 0 & 0 \\
\hline O.L. & 0 & 190 & 20 & 780 \\
\hline S.C. & 0 & 330 & 570 & 690 \\
\hline B.A. & 20 & 170 & 835 & 6,280 \\
\hline M.C. & 60 & 65 & 670 & 70 \\
\hline D.A. & 5 & 45 & 410 & 110 \\
\hline L.E.W. & 0 & 0 & 220 & 4,005 \\
\hline B.I. & 150 & 30 & 250 & 770 \\
\hline L.U. & 35 & 50 & 50 & 140 \\
\hline C.O. & 0 & 0 & 0 & 0 \\
\hline C.H. & 0 & 0 & 0 & 0 \\
\hline E.N. & 0 & 0 & 0 & 0 \\
\hline H.A. & 0 & 0 & 0 & 0 \\
\hline H.U. & 0 & 0 & 0 & 0 \\
\hline C.A.S. & 0 & 0 & 0 & 0 \\
\hline C.A.T. & 0 & 0 & 0 & 0 \\
\hline W.H. & 0 & 0 & 0 & 30 \\
\hline L.A. & 0 & 35 & 0 & 430 \\
\hline \multicolumn{5}{|c|}{$\begin{array}{l}\text { Normal controls: } \\
\qquad(n=9)\end{array}$} \\
\hline $\begin{array}{l}\text { Mean } \\
\text { Range }\end{array}$ & $\begin{array}{l}55 \\
(0-160)\end{array}$ & $\begin{array}{l}4,720 \\
(380-10,160)\end{array}$ & $\begin{array}{l}3,280 \\
(480-10,320)\end{array}$ & $\begin{array}{l}8,845 \\
(100-33,280)\end{array}$ \\
\hline
\end{tabular}

$* 1 \times 10^{6}$ non-T cells were cultured in $\mathrm{CM}$ with or without the addition of supernatant from hybrid MOP $1 \mathrm{~L}(10 \%)$ or T cell clone RAC (0.1\%). EBV from marmoset line B958 was added as indicated in Methods. A reverse hemolytic plaque assay was performed on day 6 . 
0-110). Addition of supernatant from the $\mathrm{T}$ cell helper clone RAC promoted differentiation in 10 out of 22 patients (range, 295-5,260 PFC/well) including four nonresponders to MOP 1L. Non-T cells from nine normal control individuals were induced to differentiate with both MOP 1L (range, 380$10,160)$ and RAC (480-10,320). There were no nonresponders. Interestingly, two patients (C.N. and R.O.) consistently had responses three times greater than any normal control, and a third (J.A.) had responses at the upper limits of the normal range (see below). Intracytoplasmic Ig production was determined by immunofluorescence along with the plaque data in early experiments. Non-T cells cultured in CM alone had $<1 \%$ plasma cells whereas co-culture with BCDFs, MOP $1 \mathrm{~L}$, and RAC resulted in $2-40 \%$ plasma cell generation, paralleling the data noted by reverse plaque assay (data not shown). These data suggest that $\mathrm{Ig}$ is being actively synthesized rather than just released from $B$ cells in these patients.

Differentiation of CVI non-T cells with EBV was, in general, greater in the responders (Table I), suggesting a more functionally intact B cell population. This correlation was not absolute, however, and EBV-induced PFC were usually much lower than those seen in the normal controls. There was no correlation between responsiveness to BCDF and the ability to differentiate with autologous or allogeneic T cells and PWM. As seen in Table II, the number of PFC induced with BCDF was higher than that seen with $T$ cells and PWM in most BCDF responder patients (G.R., R.O., J.A., F.E., and V.E.), including two without any PFC response to the more conventional stimulus. However, other BCDF responders had lower

Table II. Comparison of PWM and BCDF Response in Patients with CVI

\begin{tabular}{|c|c|c|c|}
\hline \multirow[b]{2}{*}{$\begin{array}{l}\text { Patient } \\
\text { (non-T cells) }\end{array}$} & \multicolumn{3}{|l|}{ PFC/well* } \\
\hline & MOP IL & $\begin{array}{l}+\mathrm{T}_{\text {2uno }} \\
+ \text { PWM }\end{array}$ & $\begin{array}{l}+T_{\text {ald }} \\
+ \text { PWM }\end{array}$ \\
\hline G.R. & 20,560 & 2,160 & $>10,000$ \\
\hline R.O. & 31,680 & 6,430 & 6,210 \\
\hline S.C. & 330 & 530 & 3,450 \\
\hline J.A. & 11,760 & 40 & 1,170 \\
\hline F.E. & 1,090 & 0 & 0 \\
\hline V.E. & 4,760 & 0 & 0 \\
\hline L.A. & 35 & $>10,000$ & $>10,000$ \\
\hline O.L. & 190 & 9,650 & 12,000 \\
\hline C.A.T. & 0 & $>20,000$ & $>20,000$ \\
\hline Normal control & 6,270 & 12,460 & $>20,000$ \\
\hline Normal control & 7,630 & 8,240 & 4,620 \\
\hline
\end{tabular}

* As per Table I.

$\ddagger 1 \times 10^{6}$ autologous $\mathrm{T}$ cells were co-cultured with $1 \times 10^{6}$ non-T cells in the presence of PWM $1 / 100$.

$\S 1 \times 10^{6}$ cells from a normal control were co-cultured with CVI non-T cells as above.
PFC responses (S.C. and O.L.) and several BCDF nonresponders displayed totally normal differentiation when co-cultured with T cells and PWM (L.A. and C.A.T.). Although the patients responding to allogeneic T cells and PWM and not autologous $T$ cells probably represent patients with active $T$ cell suppression (7), those with responses to both autologous and allogeneic $T$ cells and PWM may represent monocyte suppression $(8,13)$ or some other, as yet poorly characterized, defect. Furthermore, the ability to respond to BCDF did not correlate with the presence of active $T$ cell suppression, lack of $T$ cell helper activity, T4/T8 ratios, numbers of $\mathrm{sIg}^{+}$cells, serum Ig levels, monocyte dysfunction, therapeutic protocol, or clinical state.

Although these data give evidence for a $T$ cell defect in these patients, the low responses seen in some suggest that intrinsic B cell defects may be concomitantly present, as suggested by others $(1,4,6,19)$. Further evidence for this was noted when BCDF responders were evaluated for Ig isotype secretion. MOP 1L and RAC induce polyclonal B cell differentiation in normal controls whereas only 5 out of $11 \mathrm{MOP}$ $1 \mathrm{~L}$ responders generated IgG PFC and 1 out of 11 generated IgA PFC. Thus, the predominant B cell response was of the IgM class, and was consistent with previous reports of more immature circulating B cells in these patients (4).

Heterogeneity of $B C D F$. As noted above, four RAC responders were MOP $1 \mathrm{~L}$ nonresponders and conversely, two MOP $1 \mathrm{~L}$ responders were RAC nonresponders (Table I). These data suggest that these two factors are distinct, either acting on different cell populations or subpopulations within the B cell differentiation pathway. Since the concentration of MOP 1L or RAC used was constant throughout the study, the heterogeneity of responses was not likely to be due to differences in BCDF concentration in the supernatants themselves. Further evidence for this BCDF heterogeneity was obtained with the use of supernatants from other $\mathrm{T}$ cell hybridomas that demonstrate BCDF activity in normal non-T cells (MOW 9 and MTP 7). As seen in Table III, patients G.F., O.L., and S.I. were induced to differentiate in the presence of MOP 1L-

Table III. Heterogeneity of BCDFs

\begin{tabular}{|c|c|c|c|c|c|}
\hline \multirow[b]{2}{*}{ Patient } & \multicolumn{5}{|c|}{ PFC/well* } \\
\hline & $\begin{array}{l}\text { Medium } \\
\text { control }\end{array}$ & MOP IL & RAC & MOW 9 & MTP 7 \\
\hline R.O. & 50 & 25,360 & 8,960 & 24,230 & 23,360 \\
\hline G.F. & 0 & 1,010 & $-\ddagger$ & 0 & 0 \\
\hline O.L. & 0 & 190 & 20 & 30 & 0 \\
\hline S.I. & 0 & 600 & 0 & 0 & 0 \\
\hline C.A.T. & 0 & 0 & 0 & - & 380 \\
\hline M.C. & 60 & 65 & 670 & 6,070 & 2,845 \\
\hline L.E.W. & 0 & 0 & 220 & 235 & - \\
\hline
\end{tabular}

* As per Table I.

$\ddagger$ Not done. 
BCDF but no PFC were elicited with either RAC, MOW 9, or MTP 7. In contrast, patient M.C. generated good PFC responses with RAC, MOW 9, and MTP 7, but was an MOP $1 \mathrm{~L}$ nonresponder. The difference between MTP 7 and RAC was noted in patient C.A.T., where the former induced a PFC response while the patient was a nonresponder to the latter. Thus it appears that distinct BCDFs do exist, which may act on different stages of $B$ cell differentiation. Since patients with CVI may exhibit blocks at these various stages, some BCDFs acting on more mature B cells may not have the proper target cells.

Exaggerated BCDF response in certain CVI patients. As noted above, three patients (C.N., R.O., and J.A.) consistently demonstrated PFC responses to MOP $1 \mathrm{~L}$ well above the normal range (10-30,000 PFC/well; Table I). These patients gave normal or supranormal responses to other BCDF preparations (RAC, MTP 7, and MOW 9) as well (patient R.O.; Table III). This category of high responders was evaluated in terms of $\mathrm{T}$ cell function, cell surface markers, clinical setting, etc., and no difference was ascertained from the rest of the CVI group, although normal PFC responses were always noted with the addition of allogeneic $T$ cells and PWM. These patients might represent a BCDF deficiency state with increased cell surface receptors for $\mathrm{BCDF}$, analogous to certain hormone deficiency states (20). This hypothesis is supported by several lines of evidence. Mitogen-stimulated $T$ cell supernatants (ConA, PWM, and phytohemaglutinin) derived from these patients contained no detectable BCDF as measured by our standard assay (Table I) as well as by using the B lymphoblastoid line CESS. In contrast, normal control as well as other CVI patient $T$ cells were induced to secrete BCDF upon mitogen stimulation (data not shown). Supportive evidence for increased cell surface receptors possibility is provided by Table IV. Thirty million non-T cells from patient J.A. (experiment 1) were incubated with $0.5 \mathrm{ml}$ MOP $1 \mathrm{~L}$ supernatant or CM for $2 \mathrm{~h}$

Table IV. Preincubation of Non-T Cells with $B C D F$ for $2 h$ Is Sufficient for Differentiation

\begin{tabular}{|c|c|c|c|c|}
\hline \multirow[b]{3}{*}{$\begin{array}{l}\text { Experi- } \\
\text { ment }\end{array}$} & \multicolumn{4}{|l|}{$\mathrm{PFC} /$ well } \\
\hline & \multicolumn{2}{|c|}{ No preincubation } & \multicolumn{2}{|c|}{ Preincubation* } \\
\hline & $\begin{array}{l}\text { Medium } \\
\text { control }\end{array}$ & MOP IL & $\begin{array}{l}\text { Medium } \\
\text { control }\end{array}$ & MOP 1L \\
\hline $1 \ddagger$ & $200 \pm 20$ & $2,780 \pm 20$ & $110 \pm 10$ & $23,535 \pm 1,885$ \\
\hline $2 \S$ & 0 & $4,100 \pm 100$ & 0 & $9,900 \pm 135$ \\
\hline
\end{tabular}

* $30 \times 10^{6}$ non-T cells were incubated with $0.5 \mathrm{ml}$ MOP $1 \mathrm{~L}$ supernatant or CM for $2 \mathrm{~h}$ on ice. Cells were washed three times in CM and resuspended at $1 \times 10^{6} / \mathrm{ml}$ in macrowell cultures without additional supernatant. PFC assay was performed on day 6 as per Table I. Results were compared with cultures with supernatant present for $6 \mathrm{~d}$. $\ddagger$ Patient J.A.

$\S$ Normal control. on ice. Cells were washed free of BCDF and cultured for $6 \mathrm{~d}$ at $1 \times 10^{6}$ cells/well. Control cultures (no preincubation) were cultured in the presence of $10 \%$ MOP $1 \mathrm{~L}$ supernatant throughout the 6-d culture period. In cultures without preincubation but cultured with MOP 1L for the 6-d period, 2,780 PFC/ culture were generated, whereas exposure to BCDF only for 2 $h$ resulted in almost a 10 -fold increase of 23,535 $\mathrm{PFC} /$ culture. This is contrasted with a normal control (experiment 2), in which preincubation with BCDF induced 9,900 PFC/culture, a twofold increase over the standard BCDF assay. Thus it appears that within $2 \mathrm{~h}$ there is an interaction between non-T cells and BCDF that results in progression towards differentiation. This interaction seems to be more pronounced in our three patients (J.A., C.N., and R.O.) and may reflect an increased number of BCDF receptors on the cell surface. Further evidence for greater receptor numbers is the finding that BCDF activity in $\mathrm{T}$ cell hybridoma supernatants is more readily absorbed out with cells from these three patients, requiring 8-10-fold fewer $B$ cells than controls or other responder and nonresponder CVI patients (Table V).

\section{Discussion}

Using BCDF preparations from a cloned $\mathrm{T}$ cell hybridoma as well as an IL-2-dependent helper $T$ cell clone, we have demonstrated the ability to induce differentiation of non-T cells to antibody secreting cells in $>50 \%$ of patients with CVI. Although the range of response varied widely, half of the BCDF responders differentiated to PFC within the normal range (Table I) with responses comparable to or greater than those seen with either EBV infection or T cells and PWM. No correlation was noted between the BCDF responder group and several clinical and laboratory parameters (i.e., $\mathbf{~ S I g}^{+}$cells, serum Ig levels, functional $\mathrm{T}$ cell suppression, etc.). There was a slight correlation, however, with response to EBV infection, suggesting that response to $\mathrm{BCDF}$ supernatant required the ability to process and secrete Ig.

Previous attempts to induce differentiation within CVI cells with lectin-stimulated $T$ cell supernatants have been unsuccessful $(2,6)$ and led to the description of a B cell secretion defect in these patients. It is entirely possible that the BCDF present in the supernatants from $\mathrm{T}$ cell hybrids or clones used in this study was at a higher concentration, or alternatively, that additional factors may have been present, allowing the cells to secrete. Several recent reports suggest a more major role of the $\mathrm{T}$ cell in this disorder with either excessive suppression or lack of helper activity $(7,8,11,12)$. Although response to our factors did not appear to correlate with such $\mathrm{T}$ cell defects, this study provides further evidence that a significant proportion of these patients may indeed have normally responsive B cells to nonspecific polyclonal stimulation.

There was, however, evidence for intrinsic B cell defects in some of our BCDF responders as well, since only about half of the responders generated IgG PFC and only 1 out of 
Table V. Ability to Absorb Out BCDF (MOP $1 L)$ from Hybrid Supernatants Is Greater in CVI High Responders

\begin{tabular}{|c|c|c|c|}
\hline $\begin{array}{l}\text { Non-T cells used for } \\
\text { absorption* }\end{array}$ & $\begin{array}{l}\text { Cell No. } \\
\left(\times 10^{6}\right)\end{array}$ & $\begin{array}{l}\text { BCDF } \\
\text { (MOP 1L) }\end{array}$ & PFC/wellł \\
\hline 0 & - & - & 10 \\
\hline 0 & - & $0.1 \%$ & 8,630 \\
\hline J.A. & 2 & abs§ & 5,420 \\
\hline (CVI high & 20 & abs & 220 \\
\hline responder) & 50 & abs & 160 \\
\hline C.N. & 2 & abs & 3,520 \\
\hline (CVI high & 20 & abs & 90 \\
\hline responder) & 50 & abs & 110 \\
\hline R.O. & 2 & abs & 4,280 \\
\hline (CVI high & 20 & abs & 980 \\
\hline responder) & 50 & abs & 620 \\
\hline C.A.T. & 2 & abs & 10,320 \\
\hline (CVI non- & 20 & abs & 10,860 \\
\hline responder) & 50 & abs & 8,420 \\
\hline L.P. & 2 & abs & 8,240 \\
\hline (normal & 20 & abs & 9,360 \\
\hline \multirow[t]{3}{*}{ control) } & 100 & abs & 6,270 \\
\hline & 200 & abs & 1,140 \\
\hline & 300 & abs & 280 \\
\hline
\end{tabular}

* Varying cell concentrations were added to $0.2 \mathrm{ml}$ of a 1:100 dilution to MOP $1 \mathrm{~L}$ for $2 \mathrm{~h}$ at $4^{\circ} \mathrm{C}$ (see Table IV). Supernatant recovered after centrifugation was added at $10 \% \mathrm{vol} / \mathrm{vol}$ to $1 \times 10^{6}$ fresh non-T cells from patient J.A. Control cultures of non- $T$ cells in $C M$ or $0.1 \%$ MOP $1 \mathrm{~L}$ are shown for comparison (first two lines).

$\ddagger$ As per Table I.

$\S$ Source of BCDF is that obtained after incubation with non-T cells described in adjoining lanes. Absorbed supernatants are added at a concentration that would equal $0.1 \% \mathrm{vol} / \mathrm{vol}$ MOP $1 \mathrm{~L}$ if no absorption had occurred.

11 generated IgA PFC. This contrasts with the isotype expression in normal non-T cells cultured with any of our BCDFs where all classes of Ig are seen. The predominantly IgM response in the patients with CVI is consistent with other reports of B cell immaturity in these patients (4). Note, however, that this observation should be taken only as tentative evidence for the presence of an intrinsic B cell defect. In the case of immunodeficiency with hyper IgM it was reported that intrinsic B cell defects were responsible for the inability to switch to other Ig classes. However, with a leukemic $\mathrm{T}$ cell clone, we have been able to switch IgM B cells to secrete IgG and IgA in these patients (21; manuscript in preparation). The possibility of a defect in regulatory $T$ cells in these patients with the hyper IgM syndrome has now been postulated.

Two other findings of interest were noted in this study.
Responses to various BCDF preparations from either $T$ cell hybrids or our $\mathrm{T}$ cell clone were markedly heterogeneous. This did not appear to relate to the concentration of BCDF in any one preparation, as supernatant concentrations were kept constant. More likely, heterogeneity was elicitable owing to differences in B cell subpopulations in these patients. Blocks in B cell differentiation could occur at various stages, rendering an early blocked patient nonresponsive to a later-acting BCDF. This heterogeneity of BCDF is analogous to that described by Swain et al. (22) for B cell growth factor and Isakson et al. for $\mathrm{BCDF}_{\mu}$ and $\mathrm{BCDF}_{\gamma}(23)$. We are currently studying $\mathrm{B}$ cell subpopulations in our patients using available $B$ cell monoclonal antibodies. These data should help us determine at which stage(s) our various BCDFs work.

Finally, a subset of patients (3) with CVI was noted to have supranormal responses to the BCDF preparations. This group was characterized by their ability to respond significantly to all BCDF preparations but, as noted before, no correlation to their clinical or laboratory abnormalities could be discerned. It was postulated that these patients might represent BCDF deficiency states with associated increase in BCDF receptors on B cells, much like that seen in certain hormone deficiency states and myasthenia gravis (20). Evidence for this came from the finding that a 10-fold increase in B cell differentiation was seen after only a 2-h exposure to BCDF. Additionally, the fact that B cells from these patients can absorb out BCDF activity from supernatant at a $\log _{10}$ lower cell concentration suggests greater receptor numbers. Thus it may be possible to use cells from these high-responders to isolate the various BCDFs and their receptors and to critically evaluate receptor-ligand interaction. These patients truly appear to have a $\mathrm{T}$ cell defect, which is correctable with exogenous $T$ cell factors. More definitive evidence to support the possibility that this represents an over-expression of BCDF receptors and the lack of BCDF production in these patients would be feasible with purified $B C D F$ and monoclonal antibodies to BCDF receptors. The results of the present experiments indicate that these patients as well as other responder CVI patients might benefit by the therapeutic use of these factors, once isolated to purity.

\section{Acknowledgments}

The authors would like to thank Chris Thompson for expert technical assistance, Pamela Bolton for the preparation of this manuscript, and Alise Lion and Susan Gluckman for obtaining the blood samples.

This paper was supported by U. S. Public Health Service grants AI-19080, AI-10811, and CA-34546.

\section{References}

1. Wu, L., A. R. Lawton, and M. D. Cooper. 1973. Differentiation capacity of cultured B lymphocytes from immunodeficient patients. $J$. Clin. Invest. 52:3180-3189.

2. Geha, R. S., E. Schneeberger, E. Merler, and F. S. Rosen. 1974. Heterogeneity of "acquired" or common variable agammaglobulinemia. N. Engl. J. Med. 291:1-6. 
3. Rodriguez, M. A., A. D. Bankhurst, and R. C. Williams, Jr. 1983. Characterization of the suppressor activity in lymphocytes from patients with common variable hypogammaglobulinemia: evidence for an associated primary B cell defect. Clin. Immunol. Immunopathol. 29:35-50.

4. Pereira, S., D. Webster, and T. Platts-Mills. 1982. Immature B cells in fetal development and immunodeficiency: studies of IgM, IgG, IgA, and IgD production in vitro using Epstein-Barr virus activation. Eur. J. Immunol. 12:540-546.

5. Ciccimarra, F., G. S. Rosen, E. Schneeberger, and E. Merler. 1976. Failure of heavy chain glycosylation of IgG in some patients with common, variable agammaglobulinemia. J. Clin. Invest. 57:13861390.

6. Saiki, O., P. Ralph, C. Cunningham-Rundles, and R. A. Good. 1982. Three distinct stages of B cell defects in common varied immunodeficiency. Proc. Natl. Acad. Sci. USA. 79:6008-6012.

7. Waldmann, T. A., M. Durm, S. Broder, M. Blackman, R. H. Blaese, and W. Strober. 1974. Role of suppressor cells in pathogenesis of common variable hypogammaglobulinemia. Lancet. II:609-613.

8. Siegal, F. P., M. Siegal, and R. A. Good. 1976. Suppression of B-cell differentiation by leukocytes from hypogammaglobulinemic patients. J. Clin. Invest. 58:109-122.

9. Siegal, F. P., M. Siegal, and R. A. Good. 1978. Role of helper, suppressor, and B-cell defects in the pathogenesis of the hypogammaglobulinemias. N. Engl. J. Med. 299:172-178.

10. Schwartz, S. A., Y. S. Choi, L. Shou, and R. A. Good. 1977. Modulatory effects on immunoglobulin synthesis and secretion by lymphocytes from immunodeficient patients. J. Clin. Invest. 59:11761187.

11. Reinherz, E. L., M. D. Cooper, S. F. Schlossman, and F. S. Rosen. 1981. Abnormalities of $T$ cell maturation and regulation in human beings with immunodeficiency disorders. J. Clin. Invest. 68:699705.

12. Reinherz, E. L., R. Geha, M. E. Wohl, C. Morimoto, F. S. Rosen, and S. F. Schlossman. 1981. Immunodeficiency associated with loss of T4+ inducer T cell function. N. Engl. J. Med. 304:811-816.
13. Ashman, R. F., A. Saxon, and R. H. Stevens. 1980. Profile of multiple lymphocyte functional defects in acquired hypogammaglobulinemia, derived from in vitro cell recombination analysis. J. Allergy Clin. Immunol. 65:242-256.

14. World Health Organization. 1979. Immunodeficiency report of a WHO scientific group. Clin. Immunol. Immunopathol. 13:296.

15. Mayer, L., S. M. Fu, and H. G. Kunkel. 1982. Human T cell hybridomas secreting factors for IgA-specific help, polyclonal B cell activation and B cell proliferation. J. Exp. Med. 156:1860-1865.

16. Gronowicz, E., A. Coutinho, and F. Melchers. 1976. A plaque assay for all cells secreting Ig of a given type or class. Eur. J. Immunol. 6:588.

17. Hurley, J. N., S. M. Fu, H. G. Kunkel, G. McKenna, and M. Scharff. 1978. Lymphoblastoid cell lines from patients with chronic lymphocytic leukemia: identification of tumor origin by idiotypic analysis. Proc. Natl. Acad. Sci. USA. 75:5706-5710.

18. Bigler, R. D., D. E. Fisher, C. Y. Wang, E. A. Rinnooy Kan, and H. G. Kunkel. 1983. Idiotype-like molecules on cells of a human T cell leukemia. J. Exp. Med. 158:1000-1005.

19. Morito, T., A. D. Bankhurst, and R. C. Williams, Jr. 1980. Studies of T- and B-cell interactions in adult patients with combined immunodeficiency. J. Clin. Invest. 65:422-431.

20. Flier, J. S., C. R. Kahn, and J. Roth. 1979. Receptors, antireceptor antibodies and mechanisms of insulin resistance. $N$. Engl. J. Med. 300:413-419.

21. Mayer, L., N. Chiorazzi, F. S. Rosen, and H. G. Kunkel. 1984. Evidence for a defect in "switch" $T$ cells in patients with the hyperIgM syndrome. Clin. Res. 32:506A. (Abstr.)

22. Swain, S. L., M. Howard, J. Kappler, P. Marrack, J. Watson, R. Booth, G. D. Wetzel, and R. W. Dutton. 1983. Evidence for two distinct classes of murine B cell growth factors with activities in different functional assays. J. Exp. Med. 158:822-835.

23. Isakson, P. C., E. Pure, E. S. Vitetta, and P. H. Krammer. 1982. T cell-derived B cell differentiation factor(s). Effect on the isotype switch of murine B cells. J. Exp. Med. 155:734-748. 